\title{
The complete mitochondrial genome of the endemic and threatened killifish Orestias ascotanensis Parenti, 1984 (Cyprinodontiformes, Cyprinodontidae) from the High Andes
}

\author{
Por:Quezada-Romegialli, C (Quezada-Romegialli, Claudio) ${ }^{[1]}$; Guerrero, CJ (Jimena Guerrero, \\ Claudia) ${ }^{[2,3]}$; Veliz, D (Veliz, David) ${ }^{[2,4]}$; Vila, I (Vila, Irma) ${ }^{[2]}$
}

MITOCHONDRIAL DNA

Volumen: 27

Número: 4

Páginas: 2798-2799

DOI: 10.3109/19401736.2015.1053072

Fecha de publicación: 2016

Ver información de revista

\section{Resumen}

The killifish Orestias ascotanensis is endemic to the small isolated springs of Ascotan salt pan in the Central High Andes, Chile. Due to small populations, mining activity, and increasing aridity, this species is catalogued in danger of extinction. The complete mitochondrial genome of $O$. ascotanesis was assembled with an Ion Torrent sequencer (chip 318) that produced 2.61 million of reads. The 16617 bp of the entire genome consisted of 22 transfer RNAs, 2 ribosomal RNAs, 13 protein-coding genes, and a control region, showing that the gene composition and arrangement match to that reported for most fishes.

\section{Palabras clave}

Palabras clave de autor:Altiplano; freshwater fish; molecular phylogenetics; next-generation sequencing; NGS

KeyWords Plus:AUTOMATIC ANNOTATION; ATHERINOMORPHA; TELEOSTEI

\section{Información del autor}

Dirección para petición de copias: Vila, I (autor para petición de copias)

$+\quad$ Univ Chile, Dept Ciencias Ecol, Santiago, Chile.

\section{Direcciones:}

+ [1] Univ Antofagasta, Fish \& Isotope Ecol Lab, Fac Ciencias Mar \& Recursos Biol, Inst Ciencias Nat Alexander Humboldt, Antofagasta, Chile

$+\quad$ [2] Univ Chile, Dept Ciencias Ecol, Santiago, Chile

+ [ 3 ] Univ Santo Tomas, Fac Recursos Nat \& Med Vet, Escuela Med Vet Sede Talca, Talca, Chile

+ [ 4 ] Univ Chile, Inst Ecol \& Biodiversidad, Nucleo Milenio Ecol \& Manejo Sustentable Islas Oc, Santiago, Chile

Direcciones de correo electrónico:limnolog@uchile.cl

\section{Financiación}




\begin{tabular}{|l|l|}
\hline Entidad financiadora & Número de concesión \\
\hline FONDECYT & 1140543 \\
\hline Rector of the University of Antofagasta & \\
\hline & ICM P05-002 \\
\hline & PFB-23 \\
\hline & NC120030 \\
\hline
\end{tabular}

Ver texto de financiación

\section{Editorial}

TAYLOR \& FRANCIS LTD, 2-4 PARK SQUARE, MILTON PARK, ABINGDON OR14 4RN, OXON, ENGLAND

\section{Categorías / Clasificación}

Áreas de investigación:Genetics \& Heredity

Categorías de Web of Science:Genetics \& Heredity

\section{Información del documento}

Tipo de documento:Article

Idioma:English

Número de acceso: WOS:000377956300183

ID de PubMed: 26152352

ISSN: $1940-1736$

eISSN: $1940-1744$

Información de la revista

- Impact Factor: Journal Citation Reports ${ }^{\circledR}$

\section{Otra información}

Número IDS: DO7IQ

Referencias citadas en la Colección principal de Web of Science: 13

Veces citado en la Colección principal de Web of Science: 0 